\title{
PERBANDINGAN TINGKAT PENGETAHUAN ABORSI PADA REMAJA PUTRI DI PERKOTAAN DAN PEDESAAN
}

\author{
Zakiatul Fuada $^{1}$, Dewi Karlina Rusly ${ }^{2}$, Silvia Yasmin Lubis ${ }^{2}$ \\ ${ }^{1}$ Program Studi Kedokteran Umum, Fakultas Kedokteran, UniversitasAbulyatama \\ Aceh \\ ${ }^{2}$ Dosen Program Studi Pendidikan Dokter
}

[email korespondensi: zakiatulfuada38@gmail.com]

\begin{abstract}
Comparison of Abortion Knowledge Levels in Urban and Rural Women, 2020. Adolescents are a transitional period between children to adulthood, or teenagers. Adolescents must prepare themselves for adult life, including the sexual aspect. It takes a wise attitude from parents, educators and society in general and, of course, from the youth themselves, so that they can pass this transitional period safely so that teenagers and parents can handle this transition well. In 2011 the incidence of abortion in the world is estimated at 56 million cases $(25.6 \%)$ out of 180 million pregnancies. In the Southeast Asia region, the World Health Organization (WHO) estimates that 4.2 million abortions are performed annually. Among them, 750,000 to 2 million cases occurred in Indonesia, or it can be said that almost $50 \%$ occurred in Indonesia. This study aims to determine the knowledge of abortion in adolescents. The research method used was an analytic study with a cross sectional design. Sampling using simple random sampling technique taken from young women in Simpang Keuremat sub-district and Lhokseumawe city, totaling 214 samples. The statistical test used is the $T$ test provided that the results are seen from the $T$ value. The results of statistical tests obtained the mean value of 38.33 (SD 5.335) and the median value of 39.00 for urban adolescents and the mean value of 36.13 (SD 4.853) and the median value of 36.00 for rural adolescents, the value of $t$ count $=3.150$ (sig. 0.002 and T-count> T-table). There are differences in the level of knowledge about abortion in the sample of this study based on statistics.
\end{abstract}

Keywords: Knowledge Of Abortion, Urban Adolescents, Rural Adolescents

\begin{abstract}
Abstrak: Perbandingan Tingkat Pengetahuan Aborsi Pada Remaja Putri Di Perkotaan Dan Pedesaan, 2020. Remaja merupakan periode transisi antara anakanak ke masa dewasa, atau anak usia belasan tahun, Remaja harus mempersiapkan diri menuju kehidupan dewasa, termasuk dalamaspek seksualnya. Dibutuhkan sikap yang bijaksanadaripara orang tua, pendidik dan masyarakat pada umumnya serta tentunya dariremaja itu sendiri, agar mereka dapat melewati masa transisi itu dengan selamat supaya remaja dan orangtua dapat mengatasi transisi ini dengan baik. Pada tahun 2011 angka kejadian aborsi di dunia diperkirakan 56 juta kasus $(25,6 \%)$ dari 180 juta kehamilan. Di wilayah Asia Tenggara, World Health Organization (WHO) memperkirakan 4,2 juta aborsi dilakukan setiap tahunnya. Diantaranya 750.000 sampai 2 juta kasus terjadi di Indonesia, atau dapat dikatakan hampir 50\%nya terjadi di Indonesia. Penelitian ini bertujuan untuk mengetahui gambaran pengetahuan tentang aborsi pada usia remaja. Metode penelitian yang digunakan adalah studi analitik dengan desain cross sectional. Pengambilan sampel menggunakan teknik simple random sampling yang diambil dari remaja putri kecamatan Simpang Keuremat dan Kota Lhokseumawe yang berjumlah total 214 sampel. Uji statistik yang digunakan adalah uji T dengan ketentuan hasil dilihat dari nilai T hitung. Hasil uji statistik didapatkan hasil nilai mean 38.33 (SD 5.335) dan nilai median 39,00 pada remaja putri perkotaan dan nilai mean 36.13 (SD 4,853) dan nilai median 36,00 pada remaja putri pedesaan nilai t hitung $=3.150$ ( $\mathrm{sig}$. 0.002 dan T-hitung > T-tabel). Terdapat perbedaan tingkat pengetahuan tentang
\end{abstract}


aborsi pada sampel penelitian ini berdasarkan statistik.

Kata Kunci: Pengetahuan Aborsi, Remaja Perkotaan, Remaja Pedesaan

\section{PENDAHULUAN}

Remaja merupakan periode transisi antara anak-anak ke masa dewasa, atau anak usia belasan tahun, atau mudah terangsang perasaannya dan sebagainya.Remaja harus mempersiapkan diri menuju kehidupan dewasa, termasuk dalamaspek seksualnya. Dibutuhkan sikap yang bijaksanadaripara orang tua, pendidik dan masyarakat pada umumnya serta tentunya dariremaja itu sendiri, agar mereka dapat melewati masa transisi itu dengan selamat supaya remaja dan orangtua dapat mengatasi transisi ini dengan baik, penting untuk mengerti bagaimana dan apa yang terjadi selama transisi ini secara fisik, kognitif, sosial serta bagaimana peran orangtua dan dewasa lainnya membantu proses ini (Sarwono, 2011).

Remaja bagian dari generasi muda yang mempunyai peranan penting dalam menentukan masa depan bangsa. Pada saat ini terjadi perubahan yang cepat dalam proses pertumbuhan fisik, kognitif dan psikososial/tingkah laku serta hormonal. Arus informasi yang semakin kuat saat ini, akan menjadikan remaja dapat mengakses semua informasi dengan mudah, tanpa melakukan penyaringan mana informasi yang benar dan informasi yang salah. Kondisi ini dapat mengubah pandangan seksual remaja sehingga remaja melakukan penyimpanganpenyimpangan terhadap norma-norma yang berlaku di masyarakat, salah satunya adalah pergaulan bebas yang mengakibatkan kehamilan di luar nikah (Ayu and Kurniawati, 2017).

$$
\text { Salah satu dampak }
$$

perkembangan zaman tersebut adalah ramai perilaku seks bebas yang berbuah kehamilan di luar nikah. Ketika pelaku seks tersebut hamil diluar nikah, jarang pelakunya mempertahankan kandungan tersebut. Akibatnya mereka akan mencoba menggugurkan kandungannya atau melakukan aborsi (Akbar, 2019).

Indonesia menjadi salah satu negara yang memperhatikan para remaja agar dapat terhindar dan terjerumus ke pergaulan bebas. Hal ini merupakan upaya yang dilakukan oleh pemerintah untuk mencegah terjadinya praktek aborsi di usia dini. Aborsi merupakan masalah kesehatan yang disebabkan oleh perilaku masyarakat yang cenderung menganggap bahwa pengguguran kandungan adalah jalan terbaik dalam mengatasi kehamilan yang tidak diinginkan dan anggapan ini jelas tidak benar. Pada tahun 2011 angka kejadian aborsi di dunia diperkirakan 56 juta kasus $(25,6 \%)$ dari 180 juta kehamilan. Di wilayah Asia Tenggara, World Health Organization (WHO) memperkirakan 4,2 juta aborsi dilakukan setiap tahunnya. Diantaranya 750.000 sampai 2 juta kasus terjadi di Indonesia, atau dapat dikatakan hampir $50 \%$ nya terjadi di Indonesia. Angka tersebut memberikan gambaran, bahwa masalah aborsi di Indonesia masih cukup tinggi. Sedangkan di provinsi Aceh belum ada data resmi tentang jumlah aborsi pada remaja, begitu pula di Aceh Utara (Megasari, 2019).

Masalah aborsi tidak hanya terkait dengan kesehatan, tetapi juga erat dengan etika, moral, agama, hukum dan juga hak reproduksi wanita. Pada umumnya orang melakukan aborsi apabila terjadi kehamilan yang tidakdikehendaki karena berbagai alasan, baik didalam perkawinan ataupun diluar perkawinan. Diluar perkawinan, aborsi sering terjadi sebagai konsekuensi dari gaya hidup seperti seks bebas yang sering terjadi dikalangan remaja karena tidak hati-hati dalam memilih pergaulan. Oleh sebab itu banyak terjadi kehamilan diluar nikah sehingga menimbulkan kepanikan baik bagi wanita yang bersangkutan maupun keluarganya. Dan untuk menghindari perasaan malu kepada masyarakat, maka banyak diantara mereka yang memilih jalan keluar dari permasalahan yang sedang dihadapi yaitu dengan jalan Aborsi (Umi, Achmad Faisaol and 
Madyan, 2019).

\section{METODE}

Jenis penelitian ini bersifat analitik dengan studi cross-sectional yaitu untuk mengetahui perbandingan tingkat pengetahuan aborsi pada remaja putri diperkotaan dan pedesaan. Lokasi Penelitian di kota Lhokseumawe dan Kecamatan Simpang Keuramat Aceh Utara. Waktu penelitian dilaksanakan pada bulan Februari - Juli 2020. Berdasarkan hasil uji slovin didapatkan bahwa jumlah sampel dalam penelitian ini sebanyak 107 sampel (diambil dari jumlah data awal populasi terendah) dalam setiap populasi, hal ini mengacu pada metode pengujian menggunakan sampel yang tidak berpasangan. Kriteria Inklusi sampel 1). Remaja putri di SMPN 7 Lhokseumawe dan SMPN 1 Simpang
Keuramat, Aceh Utara Kelas I-III. Data Primer dikumpulkan dengan menggunakan kuesioner atau angket yang telah dibuat oleh peneliti kepada remaja putri di perkotaan dan pedesaan tentang pengetahuan aborsi.

\section{HASIL}

Pada pengujian univariat terhadap sampel remaja putri kota Lhokseumawe dan remaja putri desa Simpang Keuramat, Aceh Utara didapatkan hasil bahwa dari total 107 sampel remaja putri kota Lhokseumawe, nilai mean yang didapat sebesar 38.33 dengan nilai terendah yaitu 19 dan nilai tertinggi 45 . Pada remaja putri desa Simpang Keuramat dari total 107 sampel, didapatkan nilai mean sebesar 36.13 dengan nilai terendah yaitu 17 dan nilai tertinggi 45.

Tabel 1. Uji Normalitas

\begin{tabular}{crrrr}
\hline \multirow{2}{*}{ Kelompok } & \multicolumn{3}{c}{ Kolmogorov-Smirnov } \\
\cline { 2 - 5 } & Statistic & df & Sig. \\
\hline \multirow{2}{*}{ Pengetahuan Aborsi } & Remaja Desa & .099 & 107 & .311 \\
\cline { 2 - 5 } & Remaja Kota & .106 & 107 & .514 \\
\hline
\end{tabular}

Tabel 2. Distribusi frekuensi responden berdasarkan tingkat pengetahuan aborsi siswi perkotaan

\begin{tabular}{lcc}
\hline Variabel & $\boldsymbol{f}$ & Persentase \\
\hline Pengetahuan remaja putri Desa & 106 & 99.1 \\
1. Baik & 1 & 0.9 \\
2. Kurang & 106 & 99.1 \\
\hline Pengetahuan remaja putri Kota & 1 & 0.9 \\
1. Baik & & \\
2. Kurang &
\end{tabular}

Berdasarkan Tabel 2 di atas, 99.1\% dan kurang (0.9\%). Dan begitu memperlihatkan distribusi masing- juga pada variabel pengetahuan aborsi masing variabel. Pada variabel pada siswa kota dengan pengetahuan pengetahuan aborsi pada siswa desa baik sebanyak $99.1 \%$ dan kurang dengan pengetahuan baik sebanyak (0.9\%).

Tabel 3. Perbandingan tingkat pengetahuan aborsi pada remaja putri dipedesaan dan perkotaan

\begin{tabular}{ccccccc}
\hline Variabel & N & Mean & SD & T-tabel & T-hitung & Sig. \\
\hline Remaja putri Desa & 107 & 36.13 & 4.853 & 1.98238 & 3.150 & 0.002 \\
Remaja putri Kota & 107 & 38.33 & 5.335 & & & \\
\hline
\end{tabular}

Berdasarkan Tabel 3 di atas. rata dan ukuran simpangan baku dari Diperoleh adanya perbedaan nilai rata- masing-masing kelompok. Dari hasil uji t 
didapatkan nilai $\mathrm{p}$-value $=0.002$ dan Thitung > T-tabel. Hal ini menunjukkan bahwa terdapat perbedaan yang signifikan antara pengetahuan aborsi pada siswa pedesaan dan perkotaan.

\section{PEMBAHASAN}

Berdasarkan hasil yang didapatkan pada penelitian mengenai perbandingan tingkat pengetahuan remaja kota Lhokseumawe dan remaja putri desa Simpang Keuramat menunjukkan bahwa adanya perbedaan tingkat pengetahuan pada dua sampel penelitian yang diacu berdasarkan nilai mean, median dan nilai T-hitung dari tiap sampel. Hasil ini menunjukkan bahwa HO ditolak dan $\mathrm{H} 1$ dapat diterima.

Pada sampel remaja desa didapatkan nilai rata dari keseluruhan jawaban pada angket yang telah dibagikan adalah 36, 13 dan nilai median 36,00 sedangkan pada remaja perkotaan didapatkan nilai mean dari keseluruhan jawaban angket adalah 38,33 dengan nilai median 39.00. berdasarkan hasil tersebut didapatkan nilai pengetahuan tentang aborsi pada remaja perkotaan lebih tinggi dibandingkan remaja putri pedesaan. Hasil uji $T$ yang dilakukan pada penelitian ini menunjukkan bahwa nilai T hitung $>\mathrm{T}$ tabel $(3.150>1.98238)$ sehingga dapat disimpulkan bahwa tingkat pengetahuan antara remaja putri pedesaan dan remaja putri perkotaan dalam penelitian ini memiliki perbedaan berdasarkan hasil statistik.

Terdapat beberapa faktor yang dapat mempengaruhi tingkat pengetahuan seseorang, diantaranya adalah kurangnya informasi. Pemberian informasi pengetahuan aborsi berpengaruh terhadap peningkatan pengetahuan seseorang dalam memahami. Memberi informasi dapat mendukung proses dalam penyampaian materi sehingga dapat meningkatkan pengetahuan remaja (Alexander and Putri, 2018).

Pada penelitian yang dilakukan oleh Alexander dan Elise Putri, disimpulkan bahwa tidak ada hubungan pengetahuan dengan sikap terhadap aborsi pada remaja putri di SMA Taman Mulia kabupaten Kubu Raya Tahun 2017 $(p$-value $=0.91>0.05)$. Namun, mereka menyarankan untuk meningkatkan pengetahuan siswi dengan memberikan banyak informasi mengenai aborsi, serta bekerja sama dengan puskesmas atau institusi kesehatan untuk pemberian materi tentang aborsi (Alexander and Putri, 2018).

Letak geografis juga memiliki peran dalam mekanisme penyampaian informasi (Ismah and Wibiastuti, 2015) Kota Lhokseumawe yang letaknya di perkotaan akan semakin mudah untuk mendapatkan informasi tentang pengetahuan aborsi. Selain itu, perkembangan teknologi dan sarana telekomunikasi juga dapat memicu adanya peningkatan nilai informasi pengetahuan.(Habibah, 2017) Berbeda dengan Kota Lhokseumawe, Simpang Keramat yang bertempat di pedesaan dan memiliki denah perkampungan yang jauh dari pusat informasi sehingga untuk mendapatkan informasi pengetahuan terkait aborsi masih terbatas, sehingga ada perbedaan antara pengetahuan tentang aborsi.

Teman, keluarga dan guru juga memiliki peran terhadap tingkat pengetahuan. Kurangnya pemahaman tentang pengetahuan aborsi dan bisa juga dipengaruhi oleh teman-teman sebaya, orangtua, dan guru yang tergolong sangat minim dalam memberikan edukasi seputar pendidikan seksual (Susila, 2018).

Dalam penelitian "Studi komparatif pengetahuan remaja tentang penyimpangan perilaku seks di desa dan kota" yang dilakukan oleh Ida Susila pada tahun 2018 didapatkan hasil gambaran pengetahuan tentang penyimpangan perilaku seks khususnya variabel pelecehan seksual, di SMA Yapita Surabaya sebesar $54 \quad(52,4 \%)$ dengan kriteria cukup dan di MA Roudlotul Muta'abidin Lamongan sebesar $36(53,7 \%)$ dengan kriteria kurang. sehingga dapat disimpulkan tidak ada perbedaan penyimpangan perilaku seks baik di SMA Yapita Surabaya dan di MA Roudlotul Muta'abidin Lamongan. Sehingga perlu diadakan pendidikan seks khusus untuk remaja. Perbedaan dengan penelitian ini yaitu ada perbedaan 
pengetahuan tentang aborsi remaja di desa dan di kota (Susila, 2018).

Dalam penelitian yang dilakukan oleh Suci M. Ayudan Tri Kurniat ipada tahun 2017 dengan judul "Hubungan Tingkat Pengetahuan Remaja Putri Tentang Aborsi di MAN 2 Kediri Jawa Timur" didapatkan hasil 29 remaja putri $(38,7 \%)$ dengan tingkat pengetahuan tidak baik dengan mempunyai sikap tidak baik, terdapat 46 remaja putri $(61,3 \%)$ dengan tingkat pengetahuan baik yang mempunyai sikap tidak baik, terdapat 34 remaja putri $(59,6 \%)$ dengan tingkat pengetahuan tidak baik dan yang mempunyai sikap baik terdapat 23 remaja putri $(40,4 \%)$ dengan tingkat pengetahuan baik yang mempunyai sikap baik. Hasil uji chi square diperoleh $p$-value sebesar $0,027<0,05$ sehingga dapat disimpulkan ada hubungan antara tingkat pengetahuan remaja putrid tentang aborsi dengan sikap remaja terhadap aborsi. Perbedaan dengan penelitian ini yaitu meneliti tentang Perbandingan Tingkat Pengetahuan Aborsi Pada Siswi SMP di Perkotaan dan Pedesaan (Ayu and Kurniawan, 2017).

Dalam penelitian "Perbedaan Pengetahuan Remaja Putri Tentang Kehamilan Tidak Diinginkan Sebelum dan Sesudah diberikan Pendidikan Kesehatan dengan Metode Small Group Discussion di SMK Negeri 1 Pringapus" yang dilakukan oleh Astri Lestari pada tahun 2019 didapatkan hasil nilai $p$-value sebesar $0,000<a(0,05)$, ini menunjukkan bahwa ada perbedaan pengetahuan sebelum dan sesudah diberikan pendidikan kesehatan dengan metode Small Group Discussion Di SMK Negeri 1 Pringapus. Perbedaan dengan penelitian ini yaitu meneliti perbandingan pengetahuan aborsi pada siswi kota dan desa (Lestari, 2019).

\section{KESIMPULAN}

Berdasarkan penelitian yang telah dilakukan terhadap 107 sampel remaja putri kota Lhokseumawe dan 107 sampel desa Simpang Keuramat, maka dapat diambil kesimpulan bahwa tingkat pengetahuan tentang aborsi pada sampel penelitian ini memiliki perbedaan (HO ditolak dan $\mathrm{H} 1$ diterima) dengan hasil nilai mean 38.33 (SD 5.335) dan nilai median 39,00 pada remaja putri perkotaan dan nilai mean 36.13 (SD 48.53) dan nilai median 36,00 pada remaja putri pedesaan nilai $\mathrm{T}$ hitung 3.150 (sig. 0.002 dan T-hitung > Ttabel). Tingginya nilai pengetahuan mengenai aborsi pada remaja putri kota Lhokseumawe bisa disebabkan karena beberapa faktor, diantaranya; sarana informasi yang baik, berlokasi di perkotaan, serta adanya dorongan informasi baik dari keluarga maupun pendidik mengenai aborsi.

\section{DAFTAR PUSTAKA}

Akbar, A. (2019). Faktor Penyebab Abortus Di Indonesia Tahun 2010-2019: Studi Meta Analisis. Jurnal Biomedik, 11(3): 182-191. doi:10.35790/jbm.11.3.2019.266 60.

Alexander, A. and Putri, E. (2018). Hubungan Pengetahuan Dengan Sikap Terhadap Aborsi Kriminalis Pada Remaja Putri Di Sma Taman Mulia Tahun 2017. Jurnal Kedokteran, 7(2): 101-107. doi: 10.33486/jk.v7i2.6.

Ayu, S. M. and Kurniawan, T. (2017). Hubungan Tingkat Pengetahuan Remaja Putri Tentang Aborsi dengan Sikap Remaja terhadap Aborsi di MAN 2 Kediri Jawa Timur. Unnes Journal of Public Health, 6(2): 2-5.

Habibah, S. (2017). Implikasi Filsafat IImu Terhadap Perkembangan Ilmu Pengetahuan dan Teknologi. DAR El-IImi, 4: 166-180.

Ismah and Wibiastuti, E. (2015). Pengaruh Letak Geografis Sekolah Terhadap Konsentrasi Belajar Matematika Siswa Sekolah. FIBONACCI Jurnal Pendidikan Matematika \& Matematika, 1(2): 80-94.

Lestari, A. (2019). Perbedaan Pengetahuan Remaja Putri tentang Kehamilan Tidak Diinginkan Sebelum dan Sesudah Diberikan Pendidikan Kesehatan dengan Metode Small Group Discussion DI SMK 1 Pringapus. Artikel, pp. 1-9. 
Megasari, K. (2019). Perilaku Pasien Abortus dengan Kejadian Aborsi di RSUD Arifin Achmad Provinsi Riau. Menara I/mu, 13(1): 103109.

Sarwono, S. W. (2011). Psikologi Remaja. Revisi. Jakarta: Rajawali Pers.

Susila, I. (2018). Studi Komparatif Pengetahuan Remaja tentang Penyimpangan Perilaku Seks di Desa dan di Kota. 7(1): 53-62.

Umi, C., Achmad Faisaol and Madyan, S. (2019). Konsekuensi Aborsi terhadap Hak Waris (Analisa Pemikiran Para Ulama). Jurnal Ilmiah Hukum Keluarga Islam, 1(2). 